Case Reports

\title{
A Targeted Approach to Evaluating the Golfing Athlete with Low Back Pain: A Resident's Case Report
}

\author{
Luke Deckard, PT, DPT, CSOMT $^{1}$ a \\ 1 ProRehab Physical Therapy \\ Keywords: titleist performance institute, regional interdependence, movement system, low back pain, golf \\ https://doi.org/10.26603/001c.23470
}

\section{International Journal of Sports Physical Therapy}

Vol. 16, Issue 3, 2021

\begin{abstract}
Background and Purpose
Low back pain is one of the most common conditions occurring in the golfing population. Many approaches have been utilized throughout the years to address this condition including the concept of regional interdependence. The purpose of this case report is to describe the evaluation process and treatment approach of a golfer with low back pain using the principles of regional interdependence.
\end{abstract}

\section{Case Description}

A thirty-year-old male with right-sided low back pain was evaluated using a comprehensive approach including golf specific movement screening and a swing evaluation. The patient had mobility restrictions in his thoracic spine and hips that appeared to be contributing to a hypermobility in the lower lumbar spine. Based on the evaluation, he was placed into the treatment-based classification (TBC) of stabilization but would also benefit from mobilization/manipulation techniques.

\section{Outcomes}

After seven visits over a four-week span, the patient's mobility and core stability both improved and he was able to play golf and workout pain free. His outcome measures also improved, including the revised Oswestry Disability index from $26 \%$ disabled to $10 \%$, the Fear Avoidance Behavior Questionnaire (FABQ) Work from 10/42 to 3/42, and the FABQ Physical Activity from 19/24 to 6/24.

\section{Discussion}

Evaluating and developing a plan of care to address low back pain in an avid golfer can be challenging as a variety of demands are placed on the spine during the movement. This case report describes the evaluation process and treatment approach to specifically target the demands that are required during the golf swing. Utilizing a targeted approach that includes golf specific movement screening and a swing evaluation can help guide the therapist in their treatment and improve the patient's outcome.

\section{Level of Evidence}

Level 4

\section{INTRODUCTION}

Low back pain (LBP) is one of the most common conditions in the golfing population accounting for nearly $25 \%$ of total injuries. ${ }^{1-3}$ Most golfers report chronic pain that is likely due to overuse. Research has shown a greater incidence of injuries in those who played four or more rounds per week or hit over 200 balls on a weekly basis. ${ }^{2}$ Physical therapists have utilized a plethora of approaches in the treatment of this condition, moving from passive modalities to more active treatment styles. Regional Interdependence is a term that has been used more frequently in the world of physi-

\footnotetext{
a Corresponding author:

ProRehab Physical Therapy: Chenoweth 3630 Brownsboro Rd Louisville KY, 40207 Email: 1deckard@prorehablou.com
} 
A.

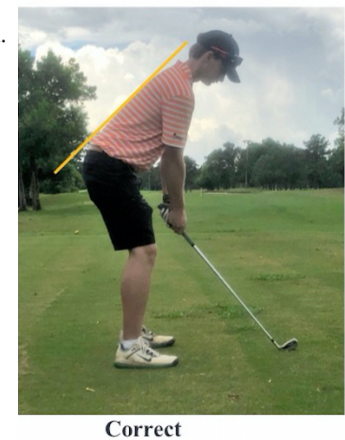

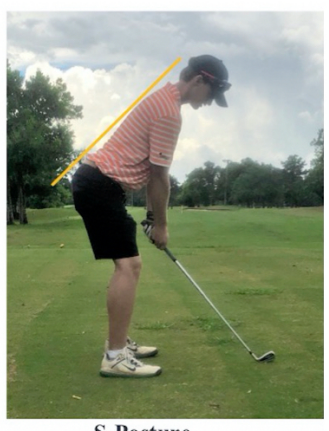

S-Posture

C.

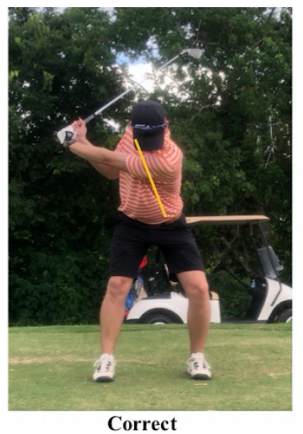

B.

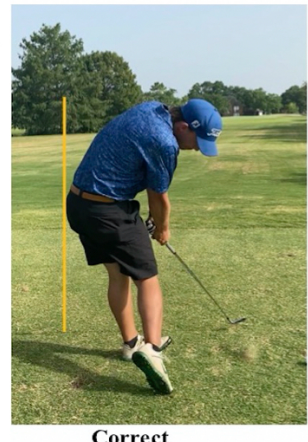

Correct

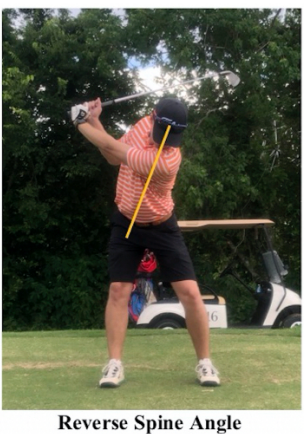

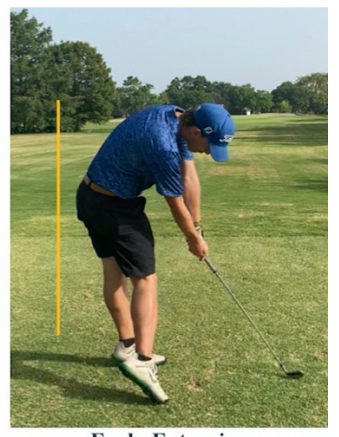

Early Extension

Figure 1: Titleist Performance Institute Top 3 golf swing characteristics related to low back pain.

A. Neutral posture vs. S-Posture, B. Normal extension vs. Early extension, C. Normal spine angle vs. Reverse spine angle.

cal therapy over the past ten years when describing one of many treatment philosophies. It is the concept of treating an adjacent segment to that of the primary region, in order to fully address the primary complaint. Mike Boyle and Gray Cook describe the body as an alternating pattern of stable segments that are connected by mobile joints that can become altered at times leading to movement dysfunctions and compensations. ${ }^{4}$ This concept can be applied throughout the body for example in the case of addressing a hip or ankle deficit in the treatment of patellofemoral pain. The current literature demonstrates a variety of treatment approaches that use this concept to address LBP including improving core stability as well as thoracic and hip mobility.

The staff of the Titleist Performance Institute (TPI) has vast experience working with golfers of all ages and handicaps and is a leading resource when it comes to golf fitness, rehabilitation, and instruction. They have developed a screening tool to help golfers raise body awareness in regard to their fitness capabilities as well as identifying golf swing characteristics that are more commonly associated with pain and dysfunction. They utilize a philosophy called the Body-Swing connection, which consists of identifying swing characteristics that are likely present based on the results from their golf specific movement screen. ${ }^{4}$ During the swing evaluation, there are twelve characteristics which the golfer is being assessed. Since the movement screen has already identified which swing characteristics are more likely to be present, it is important to pay careful attention to these specifically. Reverse spine angle (RSA), early extension, and S-posture are all found to influence the lower back during the golf swing and are likely related to an injury occurring in this region related to the number of repetitions. ${ }^{3,4}$ Depiction of each of these swing characteristics can be found in Figure 1. Several other identified factors help determine who is more likely to sustain a low back injury from playing golf. The highest predictor for LBP is having a BMI $<25.7 \mathrm{~kg} / \mathrm{m} .{ }^{2,5}$ This suggests that the tall, slender golfer is actually at a higher risk than someone with greater mass relative to their height. The second known predictor is having a right-side deficit (in right-handed golfers) of $>12.5$ seconds on the side-plank endurance test compared to the left. $^{5}$

Several authors have examined the relationship between lead and non-lead hip rotation in golfers with low back pain. A decrease in lead hip internal rotation (IR) compared to the non-lead hip has been correlated with the presence of low back pain in both amateur and professional golfers. ${ }^{6,7}$ However, the same relationship was not found when examining lead and non-lead hip rotation in LPGA tour players with a history of LBP. ${ }^{8}$ Kim et al found that lumbar axial rotation and right side bending were significantly greater in golfers with < 20 deg of passive lead hip IR at several phases throughout the golf swing. ${ }^{9}$

These findings are consistent with one of the principles used by TPI staff where a dysfunctional segment (decreased hip ROM) will lead to compensation in an adjacent region (hypermobility in the lumbar spine). Hypermobility can be described as a joint that moves outside of its expected norm. It can be identified through physiologic and accessory mobility testing. It is generally surrounded by hypomobile or stiff joints in the adjacent regions such as a lumbar hypermobility presenting with a hypomobile thoracic spine. An increase in lateral bending to the right in the lumbar spine during the impact phase (where the golfer is making contact with the ball) in golfers with limited lead hip IR is also a result of RSA. Reverse spine angle (RSA) presents with greater left side bending during the back swing (for a right-handed golfer), which has been observed in pro- 
fessional golfers with LBP. ${ }^{10}$ Pain will generally occur in the right lower back with this population as the facet joints on that side are repeatedly compressed during the downswing.

With the focus of treating low back pain expanding outside of the local musculature, the core has also become a region for further examination. When looking at lumbopelvic control in collegiate baseball pitchers, greater than $50 \%$ of the subjects demonstrated deficits that were characterized by a coupled movement pattern of the hip and low back. ${ }^{11}$ The ability to dissociate the torso from the pelvis is important in the golf swing as it allows for proper power transfer from the ground up through the legs and into the torso. Lumbo-pelvic control is an area that has not been well studied in the golfing population but needs further assessment since it is now demonstrated in other rotary athletes.

An EMG study of the golf swing found that golfers with a history of LBP have significantly earlier activation of their erector spinae during the initiation of the backswing. ${ }^{12}$ This altered pattern of activation may suggest the global muscle is acting as a primary stabilizer in this population. ${ }^{12}$ One of the tests that TPI staff recommend for core stability assessment is the pelvic tilt test. Seventy-two percent of amateurs demonstrate "shake and bake" patterns, which are vibratory movements when moving between anterior and posterior pelvic tilts. This indicates a core stability deficit and is only observed in $24.2 \%$ of PGA tour players. ${ }^{4}$

Previous researchers used the principles of regional interdependence in their approach to treating LBP in the athletic population. Lejkowski \& Poulsen completed a case report involving a 56-year-old male golfer with chronic LBP using these principles. ${ }^{13}$ With previously failed conservative treatments addressing the lumbar spine solely through a stabilization program, these authors maintained his stabilization program while also addressing the deficits found in his hip ROM. Through addressing hip ROM with manual therapy and a flexibility program, they saw a complete resolution of the patient's symptoms during and after a round of golf in two weeks (two treatment sessions). ${ }^{13}$ Kaplan used similar treatment techniques when addressing LBP in a high school athlete who played both hockey and baseball. After initially focusing on minimizing localized pain in the low back for the first two treatment sessions, they were able to decrease the patient's Oswestry Disability Index (ODI) score from $16 \%$ to $0 \%$ impaired and a global rating of change of 7 (the highest score) by more specifically addressing hip mobility and core stability over the next five visits. ${ }^{14}$ Goshtigian \& Swanson used the selective functional movement assessment (SFMA) as well as several other soft tissue mobility tests including FABER's and the Modified Thomas Test when treating an adolescent male athlete with LBP. ${ }^{15}$ Through this type of testing they identified restrictions in the soft tissue structures surrounding the hips as well as dysfunctional movement patterns throughout the spine. With treatment focused on addressing these identified dysfunctions along with treating the specific area of pain, the athlete returned to weightlifting without experiencing any pain. ${ }^{15}$

The purpose of this study was to describe the evaluation process and treatment approach used with a golfer with LBP using the principles of regional interdependence. This included TPI screening and a swing evaluation as well as treatment to the thoracic spine, core stabilizers, and hips as needed. These tests and interventions were incorporated into one treatment approach for a young male golfer with low back pain.

\section{CASE DESCRIPTION}

\section{HISTORY}

The patient was a 30-year-old male presenting with chronic right sided low back pain beginning three months ago. He reported that he "threw out his back" while getting out of his truck, which led him to being unable to move the next day and required transportation by ambulance to a hospital for treatment. Upon arrival he reported receiving an oral steroid prescription and then being discharged home to rest for a few days. Over the next few weeks, he reported taking things easy and refraining from all of his previous exercise and activity. After two to three weeks, he reported that he began playing golf and resumed his prior resistance training program with full return to all normal activities within the next month. His complaints consisted of a tight achy pain in the right lower back with prolonged sitting, sleeping (slept on his side and/or back) and with playing golf. He stated that it was typically worse the day following exercise or activity. The patient reported that he can gain relief from the pain with stretching his lower back and taking a hot shower. He reported playing a full 18-hole round of golf two times per month and is at the driving range every other day. When he is at the range, he reported that he would hit both a large and small bucket each time (approximately 150 balls) with twenty of those consisting of chips and pitches. His current workout routine consisted of rotating through chest, back, arm, and leg workouts 2-3 times each week. Overall his past medical history is unremarkable, and he is not currently taking any medications to manage his pain. His goal with physical therapy was to play golf and resistance train without LBP. The patient was informed that the data concerning his case would be submitted for publication. The U.S. Health Insurance Portability and Accountability Act (HIPPA) was discussed and an informed consent was obtained to allow for the use of his medical information.

\section{SYSTEMS REVIEW}

The results from the review of systems can be seen in Table 1 . Significant findings were found in the neuromuscular system for balance, as well as several deficits within the musculoskeletal system. The details of the deficits found in the musculoskeletal system can be found within Table 2 .

\section{CLINICAL IMPRESSION I}

With the patient's complaints of mainly right sided lower back pain beginning approximately three months prior, there were multiple diagnoses to consider for this patient. The working hypotheses were a facet joint dysfunction, lumbar intervertebral disc protrusion, and SI joint dysfunction. The hospital visit and his intake forms did not yield any positive red flag findings. The subject was referred to skilled physical therapy to address his LBP with a goal of 
Table 1: Review of Systems Results

\begin{tabular}{|l|l|}
\hline \multicolumn{2}{|c|}{ Review of Systems } \\
\hline $\begin{array}{l}\text { Cardiovascular/ } \\
\text { Pulmonary }\end{array}$ & Not formally tested \\
\hline Integumentary & No impairments \\
\hline $\begin{array}{l}\text { Cognition/ } \\
\text { Communication }\end{array}$ & Alert and Oriented $\times 3$ \\
\hline Neuromuscular & $\begin{array}{l}\text { Balance impairments as noted in his TPI screen below Dermatomes, myotomes, and DTRs were not tested } \\
\text { since radicular symptoms were not present }\end{array}$ \\
\hline Musculoskeletal & See Table 2 below for details \\
\hline
\end{tabular}

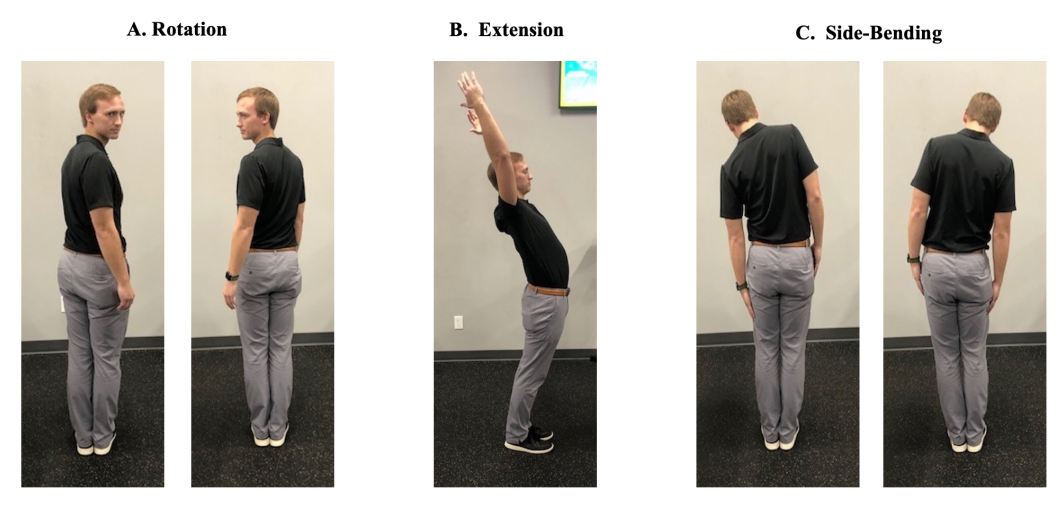

Figure 2: Positive test results from the PT exam.

A. Spinal Rotation, B. Spinal Extension, C. Spinal Side-Bending

D. Quadruped Alternating Leg Extension

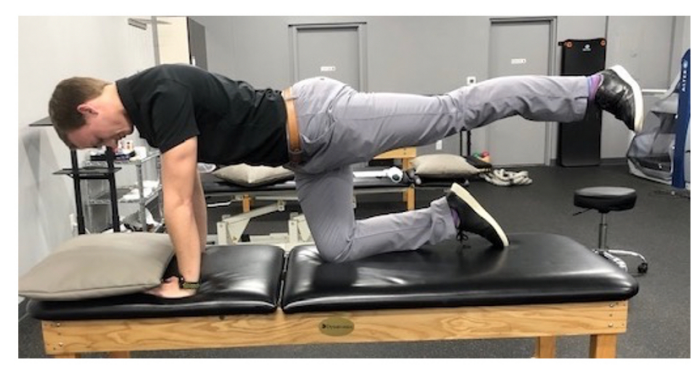

E. Supine Marching

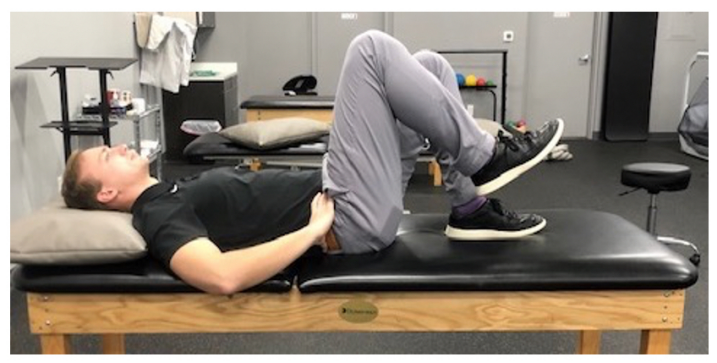

Figure 2 (continued): Positive test results from the PT exam.

D. Quadruped alternating leg extension, E. Supine Marching

returning to playing golf. Based on his history, there were concerns about his core stability and endurance as well as general mobility since he is very active and hitting a large number of range balls weekly.

\section{EXAMINATION}

\section{TEST \& MEASURES}

The results from the initial evaluation can be found in Table 2 with significant findings being represented in Figure 2 .
The patient was taken through a standard physical therapy evaluation as well as the TPI level one screen. A swing evaluation was performed after obtaining a recording that was taken at the range prior to the third visit. The results from the TPI screen as well as the patient's swing characteristics can be seen in Tables $\underline{3}$ and $\underline{4}$ respectively. Figure $\underline{3}$ presents a few of the failed tests from the TPI level one screen.

Pain was evaluated using the numeric pain rating scale from 0 to 10 where 0 is the absence of pain and 10 is the worst imaginable pain. Upon arrival the patient had re- 
Table 2: Physical Therapy Exam Findings

\begin{tabular}{|c|c|c|}
\hline \multicolumn{3}{|c|}{ Physical Therapy Evaluation } \\
\hline & Initial Exam Findings & Discharge Findings \\
\hline Spinal ROM & $\begin{array}{l}\text { Right rotation: mildly limited } \\
\text { Left rotation: moderately limited } \\
\text { Right SB: moderately limited and painful } \\
\text { Left SB: mildly limited } \\
\text { Flexion: full without pain } \\
\text { Extension: mildly limited but with pain and hinging at L4 }\end{array}$ & $\begin{array}{l}\text { Right rotation: full } \\
\text { Left rotation: full } \\
\text { Right SB: full } \\
\text { Left SB: full } \\
\text { Flexion: full } \\
\text { Extension: full without pain- hinging at L4 }\end{array}$ \\
\hline $\begin{array}{l}\text { Functional Stability } \\
\text { Testing: } \\
\text { - Alternate Hip exten- } \\
\text { sion } \\
\text { - Supine Marching }\end{array}$ & $\begin{array}{l}\text { + for extension, rotation pattern bilaterally } \\
\text { + for inability to dissociate }\end{array}$ & $\begin{array}{l}\text { + for extension, rotation } \\
\text { pattern bilaterally } \\
+ \text { for inability to dissociate on the right } \\
\text { only }\end{array}$ \\
\hline Joint Mobility & $\begin{array}{l}\text { No pain with PA gliding at any level } \\
\text { Increased mobility at L3/4/5 } \\
\text { Stiff TL junction and upper thoracic spine }\end{array}$ & $\begin{array}{l}\text { No pain with PA gliding Increased mobility } \\
\text { at L4/5 }\end{array}$ \\
\hline SLR & + for moderate hamstring tightness bilaterally & + for mild hamstring tightness bilaterally \\
\hline $\begin{array}{l}\text { Modified Thomas } \\
\text { Test }\end{array}$ & $\begin{array}{l}\text { Tight RF on the left ( } 65 \mathrm{deg} \text { ) } \\
\text { No limitation on the right }\end{array}$ & No restrictions present \\
\hline $\begin{array}{l}\text { Hip IR and ER ROM - } \\
\text { Prone }\end{array}$ & $\begin{array}{l}\text { IR: right: } 43 \text {, left: } 29 \\
\text { ER: right: } 51 \text {, left: } 56\end{array}$ & $\begin{array}{l}\text { IR: right: } 35 \text {, left: } 40 \\
\text { ER: right: } 46 \text {, left: } 41\end{array}$ \\
\hline $\begin{array}{l}\text { Functional } \\
\text { Movement/Asterisk } \\
\text { Sign }\end{array}$ & $\begin{array}{l}\text { OHS: mild forward trunk lean, slightly early butt wink, } \\
\text { increased lumbar lordosis, feet in ER } \\
\text { MSE: pain and limited }\end{array}$ & $\begin{array}{l}\text { OHS: very mild forward trunk lean, } \\
\text { slightly early butt wink, feet in ER } \\
\text { MSE: full and pain free }\end{array}$ \\
\hline Quadrant Test & Negative bilaterally & Not tested \\
\hline $\begin{array}{l}\text { Plank Holds: } \\
\text { - } \quad \text { Front } \\
\text { - } \text { Right side } \\
\text { - } \text { Left side } \\
\text { - } \text { Biering-Sorensen }\end{array}$ & $\begin{array}{l}\text { - } 41 \mathrm{sec} w / \text { pain } \\
\text { - } 16 \mathrm{sec} \\
\text { - } 19 \mathrm{sec} \\
\mathrm{sec} w / \text { pain }\end{array}$ & $\begin{array}{l}\text { - } 50 \mathrm{sec} \\
\text { - } 35 \mathrm{sec} \\
\text { - } 36 \mathrm{sec} \\
\text { - } 22 \mathrm{sec}\end{array}$ \\
\hline Hip Strength & $\begin{array}{l}\text { Posterior Glute Medius: } \\
\text { 3- } / 5 \text { bilaterally } \\
\text { Hip abduction: } \\
\text { 4-/5 bilaterally } \\
\text { Glute max: } \\
\text { 4-/5 bilaterally }\end{array}$ & $\begin{array}{l}\text { Posterior Glute Medius: } \\
\text { Lt: } 3-/ 5, \text { Rt: } 4-/ 5 \\
\text { Hip abduction: } \\
\text { Lt: } 4-/ 5, \text { Rt: } 4 / 5 \\
\text { Glute max: } \\
\text { 4-/5 bilaterally }\end{array}$ \\
\hline Pain Rating & $\begin{array}{l}\text { Current: } 1 \\
\text { Best: } 0 \\
\text { Worst: } 4\end{array}$ & $\begin{array}{l}\text { Current: } 0 \\
\text { Best: } 0 \\
\text { Worst: } 0\end{array}$ \\
\hline $\begin{array}{l}\text { Functional Outcome } \\
\text { Measures }\end{array}$ & $\begin{array}{l}\text { FABQ (W): } 10 / 42 \\
\text { FABQ (PA): } 19 / 24 \\
\text { Revised ODI: } 13 / 50\end{array}$ & $\begin{array}{l}\text { FABQ }(W): 3 / 42 \\
\text { FABQ (PA): } 6 / 24 \\
\text { Revised ODI: } 5 / 50\end{array}$ \\
\hline
\end{tabular}

Abbreviations: $\mathrm{ROM}=$ range of motion, $\mathrm{SB}=$ side-bend, $\mathrm{PA}=$ posterior to anterior, $\mathrm{TL}=$ thoracolumbar, $\mathrm{SLR}=$ straight leg raise, $\mathrm{RF}=$ rectus femoris, $\mathrm{IR}=\mathrm{internal}$ rotation, $\mathrm{ER}=\mathrm{external}$ rotation, $\mathrm{OHS}=$ overhead squat, $\mathrm{MSE}=$ multi-segmental extension, $\mathrm{FABQ}=$ Fear-avoidance behavior questionnaire, ODI= Oswestry disability index

ported his pain level at a $1 / 10$ with it being at worst a $4 / 10$ and at best a $0 / 10$. Two outcome measures were utilized to track the patient's progress over his POC. The revised Oswestry Disability Index (ODI) was utilized to measure the patient's functional disability related to his LBP. ${ }^{16}$ His initial score indicated a $26 \%$ disability due to low back pain. The Fear-Avoidance Beliefs Questionnaire (FABQ) was utilized to assess how the patient's own fear avoidance beliefs about physical activity (PA) and work (W) may contribute to his lower back pain. ${ }^{17}$ His FABQ W was $10 / 42$ and his FABQ PA was 19/24. During the examination, the subject demonstrated deficits in both mobility as well as stability throughout the trunk and lower extremities. Care was taken to examine the ROM above and below the painful region, joint mobility, soft tissue extensibility, and core stability. Spine ROM was evaluated using the Selective Functional Movement Assessment (SFMA) top tier for multi-segmental flexion, extension, and rotation, as well as frontal plane sidebending. He demonstrated limitations in his spinal ROM in all planes with the exception of flexion being full. Limitations were also found in hip internal rotation bilaterally. After examining his spinal ROM in standing, an overhead deep squat was used for a functional movement assessment. During this movement he demonstrated several deficits including a mild forward trunk lean, increased lumbar lordosis, an early posterior tilting of the pelvis before the hips reach parallel, and he elected to use an externally rotated position for his feet. Accessory mobility utilizing posterior to an- 
Table 3: Titleist Performance Institute Level One Screen Results

\begin{tabular}{|c|c|c|}
\hline \multicolumn{3}{|c|}{ TPI Level One Screen } \\
\hline & Initial & Discharge \\
\hline Setup Posture & S-posture & Neutral \\
\hline Pelvic Tilt* & Cannot arch the back, shake and bake quality & $\begin{array}{l}\text { Can pelvic tilt in both directions, shake and bake } \\
\text { quality }\end{array}$ \\
\hline $\begin{array}{l}\text { Pelvic } \\
\text { Rotation* }\end{array}$ & $\begin{array}{l}\text { Limited bilaterally without assistance, no improvement } \\
\text { with assistance, some LBP on the right }\end{array}$ & $\begin{array}{l}\text { Limited bilaterally without assistance, improves } \\
\text { in each direction with assistance }\end{array}$ \\
\hline $\begin{array}{l}\text { Torso } \\
\text { Rotation }\end{array}$ & $\begin{array}{l}\text { Limited turning right without assistance, improves with } \\
\text { assistance }\end{array}$ & $\begin{array}{l}\text { Limited turning right without assistance, } \\
\text { improves with assistance }\end{array}$ \\
\hline $\begin{array}{l}\text { Overhead } \\
\text { Deep Squat }\end{array}$ & $\begin{array}{l}\text { Arms down limited, Good DF bilaterally, weight evenly } \\
\text { distributed }\end{array}$ & $\begin{array}{l}\text { Arms down limited, Good DF bilaterally, weight } \\
\text { evenly distributed }\end{array}$ \\
\hline Toe-Touch & Normal & Normal \\
\hline $90-90^{*}$ & $\begin{array}{l}\text { Right side }>\text { spine angle, same in golf posture Left side }= \\
\text { spine angle, same in golf posture }\end{array}$ & > Spine angle in both positions bilaterally \\
\hline $\begin{array}{l}\text { Single-leg } \\
\text { Balance* }\end{array}$ & $0-5$ seconds bilaterally & $\begin{array}{l}6-10 \text { seconds on the right } 0-5 \text { seconds on the } \\
\text { left }\end{array}$ \\
\hline $\begin{array}{l}\text { Lat Length } \\
\text { Test* }^{*}\end{array}$ & Between the nose and wall bilaterally & $\begin{array}{l}\text { Left side touches the wall Right side between } \\
\text { the nose and wall }\end{array}$ \\
\hline $\begin{array}{l}\text { Lower } \\
\text { Quarter } \\
\text { Rotation }\end{array}$ & Limited rotation bilaterally in backswing and downswing & $\begin{array}{l}\text { Limited rotation bilaterally in backswing and } \\
\text { downswing }\end{array}$ \\
\hline $\begin{array}{l}\text { Seated Trunk } \\
\text { Rotation* }\end{array}$ & Right side $>45$ deg Left side $=$ to $45 \mathrm{deg}$ & $>45$ deg bilaterally \\
\hline $\begin{array}{l}\text { Bridge } w / \text { Leg } \\
\text { Extension }\end{array}$ & Weak glutes bilaterally & Weak glutes bilaterally \\
\hline $\begin{array}{l}\text { Cervical } \\
\text { Rotation }\end{array}$ & Normal & Normal \\
\hline $\begin{array}{l}\text { Forearm } \\
\text { Rotation }\end{array}$ & Normal & Normal \\
\hline Wrist Hinge & Normal & Normal \\
\hline Wrist Flexion & Normal & Normal \\
\hline $\begin{array}{l}\text { Wrist } \\
\text { Extension }\end{array}$ & Normal & Normal \\
\hline $\begin{array}{l}\text { Fitness } \\
\text { Handicap }\end{array}$ & 36 & 21 \\
\hline
\end{tabular}

Abbreviations: $\mathrm{LBP}=$ low back pain, $\mathrm{DF}=$ dorsiflexion

*Change in test results from initial to discharge

terior springing revealed a stiff thoracic spine particularly from T6-T12 with hypermobile segments at L3/4 and L4/5 but without any pain reproduction. The Modified Thomas test and straight leg raise (SLR) were used to assess soft-tissue extensibility of the hip musculature. The SLR demonstrated hamstring tightness bilaterally where the modified Thomas test demonstrated a tight rectus femoris on the left leg. Core endurance and functional stability were assessed using plank holds for max time as well as supine marching (hook lying alternating hip flexion), and alternating hip extension in quadruped. His plank times revealed that he had poor core endurance for his age in each direction and was limited by pain in his front plank at forty-one seconds and his Biering-Sorensen hold at eight seconds. Both of his functional stability tests (quadruped alternating hip extension and supine marching) revealed poor motor control strategies with the inability to disassociate his hip mo- tion from his lower back. When assessing his alternating hip extension in quadruped, the subject moved into an extension-rotation pattern incorporating the lower back into the movement. With supine marching he demonstrated moderate movement at his ASIS with each march.

The TPI level one screen was used to assess movement and identify deficits within his golf posture, particularly any that are limited related to pain provocation. Initially he demonstrated deficits with his set up posture as well as upper and lower body dissociation. According to data collected by TPI, setting up in an S-posture places him at a higher risk for low back pain because of the stress it places on the facet joints of the spine. This may be one of the reasons for failing the pelvic tilt test since the player is unable to "arch their back" as they are already in this posture with their setup. ${ }^{4}$ With the pelvic rotation test, he demonstrated deficits in both directions and the pain in his lower 
Table 4: Swing Evaluation Results

\begin{tabular}{|l|c|c|}
\hline \multicolumn{2}{|c|}{ The Big 12 Swing Characteristics } & Initial \\
\hline & - & Discharge \\
\hline S-Posture* & - & - \\
\hline C-Posture & + & + \\
\hline Loss of Posture & - & - \\
\hline Flat Shoulder Plane & + & + \\
\hline Early Extension* & - & - \\
\hline Over-the-Top & + & - \\
\hline Sway & + & + \\
\hline Slide & + & + \\
\hline Reverse Spine Angle (RSA)* & - & - \\
\hline Hanging Back & - & - \\
\hline Casting/Early release/Scooping & - & - \\
\hline Chicken Winging & + & \\
\hline
\end{tabular}

*Increased frequency in golfer's with LBP

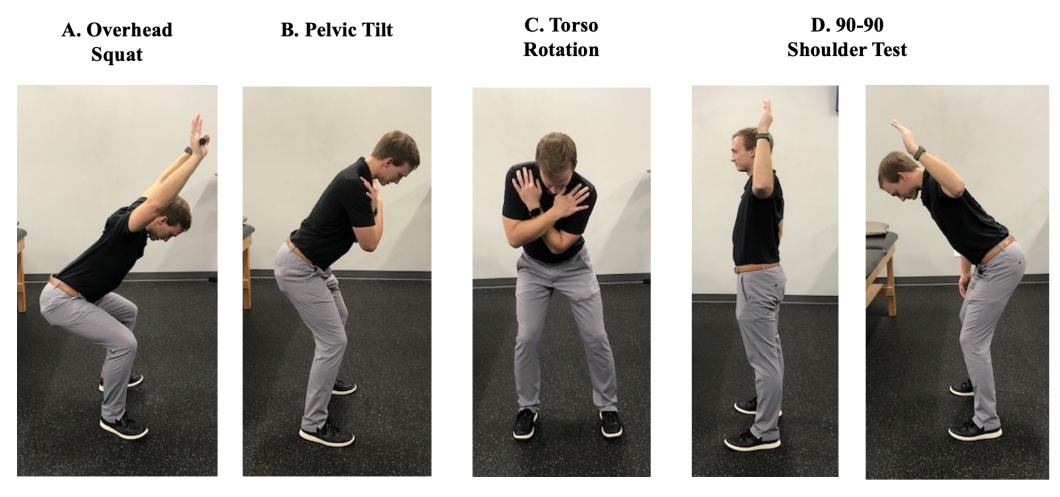

Figure 3: Failed tests from the Titleist Performance Institute level one screen at the initial eval.

A. Overhead Squat, B. Pelvic Tilt, C. Torso Rotation D. 90-90 Shoulder test
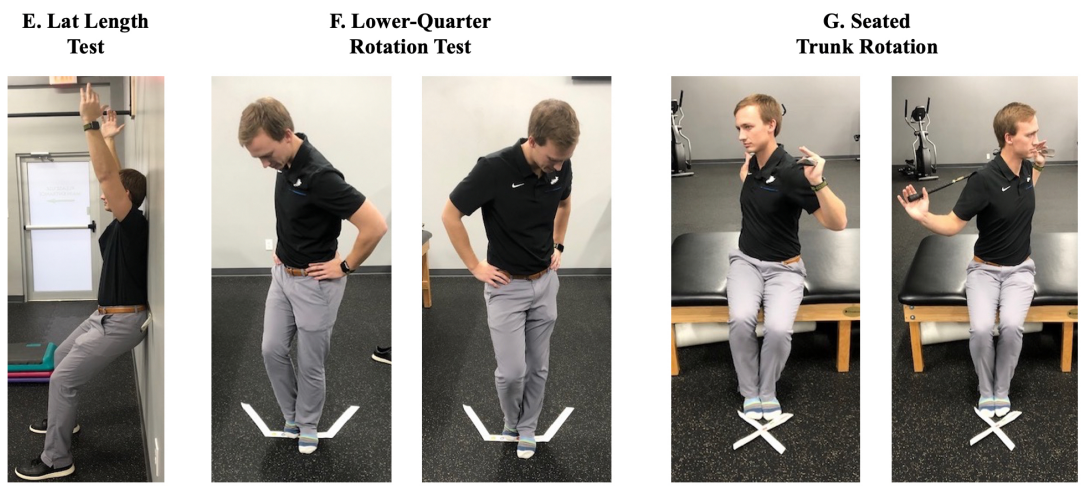

Figure 3 (continued): Failed tests from the Titleist Performance Institute level one screen at the initial eval.

E. Lat length test, F. Lower quarter rotation test, G. Seated trunk rotation

back was reproduced. When external stability was provided there were no improvements in this test indicating a likely mobility deficit. Torso rotation showed a deficit when turning to the right (his down swing) and improved when ex- 
ternal support was provided, again indicating a likely stability deficit. His overhead deep squat indicated that there were likely deficits in the thoracic spine due to his forward trunk position as well as the hips/knees since he demonstrated appropriate dorsiflexion bilaterally when assessed in half kneeling. Since these areas were already identified in the physical therapist's exam, special attention was paid to the upcoming tests to see if the findings would remain consistent. When assessing his single leg balance with his eyes closed, he demonstrated large deficits with times between 0 and 5 seconds bilaterally. He also showed significant deficits with his lower quarter rotation testing with limitations in both hips in his backswing and downswing. With latissimus dorsi length testing performed in a mini squat position against the wall, he demonstrated mild limitations bilaterally being unable to touch the wall while maintaining a neutral spine. The seated trunk rotation test showed limitations with turning to the left which would be toward his backswing. The last deficit that was found during the TPI screen was that the subject demonstrated weak gluteal musculature bilaterally during the bridge with leg extension test. All other tests demonstrated acceptable/ passing levels.

Based on the body-swing connection, his TPI level one screen would suggest that he was at a very high likelihood for demonstrating the following characteristics: S-posture, loss of posture, early extension, sway, slide, hanging back, and reverse spine angle (RSA). When performing a swing evaluation utilizing down-the-line view (from behind the player) and face-on view (facing the player) several of these characteristics were confirmed. From the down-the-line view of the patient's golf swing two characteristics were identified: early extension and loss of posture. The face-on view of his golf swing identified swaying, sliding, and RSA. Despite setting up in S-posture during his screen, he did not demonstrate this characteristic when setting up to hit a golf ball.

\section{CLINICAL IMPRESSION II}

Based on the examination findings, this patient was placed into the treatment-based classification of stabilization and was designated with a PT diagnosis of chronic low back pain with movement coordination impairments. He demonstrated some findings that would suggest that mobilization/ manipulation techniques would also be important to include in his plan of care. It was noted that the subject had demonstrated a hypermobile segment in the L4-5 region with accessory mobility testing that was consistent with his hinge point during his spinal extension. The lumbar spine was surrounded by a stiff thoracic spine and mobility deficits in his left hip. The large deficits in his core stability, as demonstrated by his plank times and functional stability tests (alternate leg extension in quadruped and supine marching), suggested that with the repeated microtrauma of the golf swing, he may have experienced excessive stress in the lumbar spine. These limitations are consistent with the theory of regional interdependence as previously discussed. The risk for an injury is higher when a stable joint begins to sacrifice its role in order to obtain mobility that has been lost in the adjacent joints. ${ }^{4}$
The swing characteristics identified were consistent with the findings in his physical therapy evaluation. Early extension and RSA are two of the three characteristics that have a high correlation with low back pain in golfers and would seem to be related to the extension rotation pattern that he utilized during other movements. Identifying sway and slide during his swing are supported by the weak lateral hip musculature that was identified upon exam.

\section{PROGNOSIS}

Based on the subject's age, motivation, active lifestyle, and lower FABQ scores he was designated with a good prognosis for recovering from his chronic LBP. With improvements in his spinal and hip mobility, core stability, lower extremity strength, and education on his golf swing and overall volume, it was anticipated that he would be able to make a full return to playing golf and lifting weights without experiencing any pain or discomfort. Discharge criteria would consist of a full return to activity and completing the TPI screen without experiencing pain or discomfort.

\section{INTERVENTIONS}

\section{PATIENT EDUCATION}

Therapists provided education to the patient including his PT diagnosis, plan of care (POC), prognosis with skilled physical therapy, as well as a home exercise program (HEP). The initial goal of his POC was to modify his activity level during his range sessions and then begin to address his mobility deficits, which should help to reduce the stress to his lower back. The initial HEP consisted of open books (side lying thoracic rotation) to address deficits in thoracic spine mobility, a prone quad stretch to address soft tissue extensibility at the hips, and front planks and a modified side plank to begin addressing his core stabilization deficits. Education was provided concerning the swing characteristics that he had demonstrated during the evaluation, particularly the ones that placed him at a higher risk for low back pain. Discussion of the best sleep postures was also completed with education on trying to maintain a neutral spine when sleeping on his side and to minimize prone/stomach sleeping postures. The final aspect of his HEP consisted of education regarding the volume of golf balls that he was hitting during his range sessions (approximately 130 full swings) in comparison to the amount necessary to complete a round of golf (40-60 full swings depending on golf handicap). ${ }^{3}$

\section{PROCEDURAL INTERVENTIONS}

The subject was treated for seven visits over a span of four weeks. The visits ranged from 50-60 minutes in duration and began at two visits a week before decreasing to one visit the last week. Intervention consisted of manual therapy and therapeutic exercise, predominantly. Manual therapy techniques consisted of grade III/IV posterior hip mobilization and mobilizations with movement for hip rotation as well as spinal manipulation to both the thoracic and lumbar spine. Therapeutic exercise consisted of flexibility, strength, core stabilization, and motor control activities. 
Asterisk signs, which can be defined as a movement that reproduces the patient's pain, were utilized throughout each treatment session to check his progress towards his goals and consisted of multi-segmental extension and an overhead squat.

With the initial goals of decreasing his pain and improving his spinal mobility, high velocity- low amplitude anterior-posterior (AP) thrusts were performed to both the thoracic and lumbar spines during the first session. This improved his multi-segmental rotation to normal levels bilaterally. Manual therapy was followed by the HEP that was mentioned above to address this mobility deficit and initiate early core stabilization activities until the first follow up appointment. Detailed outlines of each session can be found in Table 5.

Each subsequent session began with an aerobic warmup activity which consisted of the elliptical to encourage some spinal rotation with the use of the arms and then progressing to the rower to increase the aerobic demands. The aerobic warm-up was followed by re-checking the previous asterisk signs, multi-segmental extension (MSE) and multi-segmental rotation (MSR). During the first few sessions these motions continued to demonstrate deficits but were without pain. Manual therapy consisting of a supine CT junction/lower thoracic manipulation and a side-lying lumbar gapping manipulation targeting the upper lumbar spine were then applied to address these deficits, followed by a re-assessment of the asterisk signs. Upon reviewing these motions, he demonstrated full multi-segmental rotation (MSR) and multi-segmental extension (MSE) without pain. After completing the manual therapy interventions, the patient began performing therapeutic exercise. The first exercises were focused on addressing his mobility deficits. These consisted of activities focused on the thoracic spine, bilateral hips, as well as soft-tissue extensibility of the lower extremities. Motor control and core stability activities were then performed consisting of items from the initial evaluation including plank holds and quadruped alternating leg extensions. These activities were progressed throughout the plan of care to include lifts and rows while maintaining proper positioning, as well as becoming more golf specific. Motor control exercises consisted of working on upper and lower body dissociation initially with support from a dowel rod and trying to perform them in a golf posture. Beginning on the fourth visit, a dynamic warm up followed his aerobic activity with an emphasis on functional movements to generate improved spine and hip mobility. This visit also initiated the use of circuits to begin training his muscles and skills under fatigue as well as lower extremity strengthening activities targeting the gluteal musculature and lateral stabilizers of the hips.

As he continued to progress, the warm-up was adjusted to using the rowing machine to help build further cardiovascular endurance and incorporate full body mobility from the ankles up through the spine. Manual therapy shifted to focus more on the hips since his spinal mobility had consistently improved over the first few sessions and was consistently maintained at a full level upon his arrival to the clinic. With deficits present in hip flexion, as noted by the early posterior pelvic tilt in his squat and with his hip rotation in prone, techniques were used to help improve these motions and then followed up with further hip mobility activities. Circuit training was now also being utilized during his strength exercises and activities were progressed with a few single-leg exercises to further address the lateral hip stabilizers.

His HEP was updated throughout the POC as new exercises were incorporated into his program and mastery was displayed by the subject in the clinic. After the last session, a more detailed program was emailed to the patient that consisted of exercises that had been performed in the clinic and that could be completed at home with minimal equipment. He was educated on the importance of completing this program a few times weekly to continue making progress since our POC was shortened due to COVID-19 restrictions. Table $\mathbf{6}$ shows his updated HEP that was sent after he was discharged.

\section{OUTCOMES}

The subject of this study showed excellent progress towards his goals. He demonstrated full spinal ROM, improved hip mobility in both joint play and soft tissue extensibility, and improvements in all of his plank holds without any pain. He did not reach the goals for his plank times to exceed one and a half minutes for the front hold and for $>1 \mathrm{~min}$ in all other planes, but they were tested at four weeks instead of six weeks due to the shortening of his POC based on COVID-19 restrictions. Despite his functional stability testing still being (+) for the inability to fully dissociate hip movement from the lower back, his awareness of his body in space during these motions was improved. When assessing his improvements based on his functional outcome measures, both showed large improvements after four weeks. His revised ODI improved 16\% from 26\% disabled to $10 \%$. The Minimally clinically important difference (MCID) has not been established with this outcome measure when it comes to non-specific LBP, therefore not allowing a determination to be made if this change was clinically significant. His FABQ W score improved from 10/42 to 3/42 and his FABQ PA improved from $19 / 24$ to $6 / 24$. The accepted MCID for acute low back pain with the FABQ is 13 points, which would show clinical significance for the physical activity portion. ${ }^{18}$ Although his timeframe falls out of this stage, this is the most appropriate data available at this time. Full details can be seen in Table 2 from status at discharge. Overall, he was able to achieve his goal of being pain free after golfing and working out.

His TPI level one screen showed improvements as well moving from a fitness handicap of 36 with pain present during the pelvic rotation test to a 21 without any pain experienced. A few tests of importance were that he was able to pelvic tilt in both directions though still demonstrating a "shake and bake" quality, his seated trunk rotation was full in both directions, and his pelvic rotation test was pain free and did improve with support showing that it was more limited by his ability to stabilize. A more detailed report of his screening results can be seen in Table 3 . Tests that had improvements have been marked with an asterisk (*).

At this time, the Body-swing connection would suggest that he still had a high likelihood of demonstrating the following characteristics: sway, slide, loss of posture, early ex- 
Table 5: Individual Treatment Sessions

\begin{tabular}{|c|c|}
\hline & Interventions \\
\hline $\begin{array}{l}\text { Treatment } \\
\text { Day } 1 \text { (I.E) }\end{array}$ & $\begin{array}{l}\text { MT: Spine CT/Lower Thoracic manipulation, Lumbar gapping manipulation } \\
\text { HEP: Open books (side lying thoracic rotation), Prone Quad stretch, Front plank holds x } 30 \mathrm{sec} \text {, Modified Side plank } \\
\text { hold } \times 20 \mathrm{sec}\end{array}$ \\
\hline $\begin{array}{l}\text { Treatment } \\
\text { Day } 2\end{array}$ & $\begin{array}{l}\text { MT: Spine CT/Lower Thoracic manipulation, Lumbar gapping manipulation } \\
\text { TE: } \\
\text { Warm-up: Elliptical x } 8 \text { min, } \\
\text { Mobility: Open books (side lying thoracic rotation) } \times 15 \text { bilaterally, Thread the needle (quadruped thoracic flexion/ } \\
\text { rotation) } \times 15 \text { bilaterally, Quadruped rock backs } \times 10 \text { with hips neutral, } \times 10 \text { with hips in IR, HK OH trunk rotations } \times \\
10 \text { each side, Couch stretch (HK hip flexor + rectus femoris stretch) with posterior pelvic tilt } 3 \times 30 \text { sec, } \\
\text { Motor Control: Alternating leg extensions in quadruped } 2 \times 10 \text { each side, Dead Bugs (spine alternating arm flexion + } \\
\text { leg extension) } 2 \times 10 \text { each side, Single leg hip rotation with dowel assist } 2 \times 10 \text { each side } \\
\text { Core Stability: Front Plank holds } 3 \times 30 \text { sec, Modified Side-plank holds } 3 \times 20 \text { sec each side } \\
\text { HEP: Open books (side lying thoracic rotation), Prone Quad stretch, Front plank holds } \times 30 \text { sec, Modified Side plank } \\
\text { hold } \times 20 \text { sec }\end{array}$ \\
\hline $\begin{array}{l}\text { Treatment } \\
\text { Day } 3\end{array}$ & $\begin{array}{l}\text { MT: Spine CT/Lower Thoracic manipulation, Lumbar gapping manipulation } \\
\text { TE: } \\
\text { Warm-up: Elliptical } \times 8 \text { min, } \\
\text { Mobility: Thread the needle (quadruped thoracic flexion/rotation) } \times 15 \text { bilaterally, Cat/Camel (quadruped spinal } \\
\text { flexion/extension) } \times 10 \text { each, Quadruped rock backs } \times 10 \text { with hips neutral, } \times 10 \text { with hips in IR, HK OH trunk } \\
\text { rotations } \times 10 \text { each side, } \\
\text { Motor Control: Bird dogs (quadruped alternating shoulder flexion + leg extension) } 2 \times 10 \text { each side, Dead Bugs } \\
\text { (supine alternating arm flexion +leg extension) } 2 \times 10 \text { each side, HK chops without trunk motion } 2 \times 10 \text { each side } \\
\text { with blue TB, Single leg hip rotation with dowel assist } 2 \times 10 \text { each side, Torso Turns with hips blocked at wall } 2 \times 10 \\
\text { each side } \\
\text { Core Stability: Front Planks with leg extension lifts } 3 \times 30 \text { sec, Modified Side-plank holds with } 5 \mathrm{lb} \text { DB row } 2 \times 15 \\
\text { each side } \\
\text { HEP: Open books (side lying thoracic rotation), Prone Quad stretch, Front plank holds } \times 30 \text { sec, Modified Side plank } \\
\text { hold } \times 20 \text { sec }\end{array}$ \\
\hline $\begin{array}{l}\text { Treatment } \\
\text { Day } 4\end{array}$ & $\begin{array}{l}\text { MT: Spine CT/Lower Thoracic manipulation, Lumbar gapping manipulation } \\
\text { TE: } \\
\text { Warm-up: Elliptical x } 8 \text { min, World's greatest stretch (split stance thoracic rotation with opposite hand on the } \\
\text { ground), Walking figure 4, Reverse toe-touch into inchworm x } 10 \text { yards each } \\
\text { Mobility: Quadruped rock backs } \times 20 \text { each with leg in cross body position, Leg elevated lunge for posterior hip } \\
\text { mobility } \\
\text { Motor Control: } \\
\text { Circuit A } 2 \text { rounds: Bird Dogs (quadruped alternating shoulder flexion + leg extension) } \times 10 \text { each side, Dead Bugs } \\
\text { (supine alternating shoulder flexion + leg extension) } \times 10 \text { each side, } \\
\text { Circuit B } \times 2 \text { rounds: Hip rotation with dowel assist } \times 10 \text { each side, Torso Turns with hips blocked at wall } \times 10 \text { each } \\
\text { side } \\
\text { Core Stability: HK chops without trunk motion } 2 \times 10 \text { each side with blue TB, Split stance paloff press } 2 \times 15 \text { each } \\
\text { side with medium strength band } \\
\text { Strength: Side-stepping with green band at knees } 2 \times 20 \text { yards, Kettlebell Deadlift with } 12 \mathrm{~kg} 3 \times 10 \text {, Lateral } \\
\text { eccentric tap downs from } 4 \text { in step } 2 \times 12 \text { each side } \\
\text { HEP: Open books (side lying thoracic rotation), Prone Quad stretch, Front plank holds } \times 30 \text { sec, Modified Side plank } \\
\text { hold } \times 20 \text { sec, WGS (split stance thoracic rotation with opposite hand on the ground), Quadruped figure } 4 \text { rock } \\
\text { backs, leg elevated lunges }\end{array}$ \\
\hline $\begin{array}{l}\text { Treatment } \\
\text { Day } 5\end{array}$ & $\begin{array}{l}\text { MT: Spine CT/Lower Thoracic manipulation, Lumbar gapping manipulation, Posterior hip mobilization grades III/IV } \\
\text { bilaterally, Hip IR/ER mobilization with movement (MWM) bilaterally } \\
\text { TE: } \\
\text { Warm-up: Rower } \times 500 \text { meters, World's greatest stretch (split stance thoracic rotation with opposite hand on the } \\
\text { ground), Walking figure } 4 \text {, Reverse toe-touch into inchworm } \times 10 \text { yards each } \\
\text { Mobility: Quadruped rock backs } \times 20 \text { each with leg in cross body position, Leg elevated lunge for posterior hip } \\
\text { mobility } \\
\text { Motor Control: } \\
\text { Circuit A } 2 \text { rounds: Bird dogs (quadruped alternating shoulder flexion + leg extension) } 2 \times 10 \text { each side, Dead Bugs } \\
\text { (supine alternating shoulder flexion + leg extension) } 2 \times 10 \text { each side, both using red TheraBand for resistance Single } \\
\text { leg Romanian Dead lifts with dowel assist } 2 \times 10 \text { each side } \\
\text { Core Stability and Strength: } \\
\text { Circuit B } \times 2 \text { rounds: Split stance paloff press } \times 15 \text { each side with medium strength band, Side-stepping with green } \\
\text { band at knees } \times 20 \text { yards, Single-leg hip thruster } \times 8-10 \text { from bench } \\
\text { Circuit C } \times 2 \text { rounds: Front plank with leg extension lifts } \times 10 \text { each leg, Kettlebell Deadlift with } 12 \text { kg } \times 12 \text {, Lateral } \\
\text { eccentric tap downs from } 4 \text { in step } 2 \times 12 \text { each side } \\
\text { HEP: Open books (side lying thoracic rotation), Prone Quad stretch, Front plank holds } \times 30 \text { sec, Modified Side plank } \\
\text { hold } \times 20 \text { sec, WGS (split stance thoracic rotation with opposite hand on the ground), Quadruped figure } 4 \text { rock } \\
\text { backs, leg elevated lunges }\end{array}$ \\
\hline
\end{tabular}




\begin{tabular}{|c|c|}
\hline & Interventions \\
\hline $\begin{array}{l}\text { Treatment } \\
\text { Day } 6\end{array}$ & $\begin{array}{l}\text { MT: Posterior hip mobilization grades III/IV bilaterally, Hip IR/ER mobilization with movement (MWM) bilaterally } \\
\text { TE: } \\
\text { Warm-up: Rower x } 750 \text { meters, World's greatest stretch (split stance thoracic rotation with opposite hand on the } \\
\text { ground), Walking figure } 4 \text {, Reverse toe-touch into inchworm } \times 16 \text { yards each } \\
\text { Mobility: Quadruped rock backs } \times 20 \text { each with leg in cross body position, Leg elevated lunge for posterior hip } \\
\text { mobility } \\
\text { Motor Control: } \\
\text { Circuit A } 2 \text { rounds: Torso turns with hips blocked at wall } \times 10 \text { each side, Pelvic rotations while maintaining ball } \\
\text { against wall in golf posture } 10 \text { each side, Single leg hip rotation with dowel assist } \times 10 \text { each side } \\
\text { Core Stability and Strength: } \\
\text { Circuit B } \times 2 \text { rounds: Single leg Romanian Dead lifts with dowel assist } \times 10 \text { each side, Single-leg hip thruster } \times 8-10 \\
\text { from bench, Side-step up with opposite knee drive with torso angled away from box with } 4 \text { kg KB ball hold } \times 10 \text { each } \\
\text { side } \\
\text { Circuit C } \times 2 \text { rounds: Front plank with leg extension lifts } \times 12 \text { each leg, Goblet squat with } 15 \mathrm{lb} \text { KB } \times 12 \text {, Modified } \\
\text { side-plank with } 5 \mathrm{Ib} \text { DB row } \times 15 \text { each side } \\
\text { Split stance Paloff press } \times 15 \text { each side with medium strength band } \\
\text { HEP: Open books (side lying thoracic rotation), Prone Quad stretch, Front plank holds } \times 30 \text { sec, Modified Side plank } \\
\text { hold } \times 20 \text { sec, WGS (split stance thoracic rotation with opposite hand on the ground), Quadruped figure } 4 \text { rock } \\
\text { backs, leg elevated lunges }\end{array}$ \\
\hline $\begin{array}{l}\text { Treatment } \\
\text { Day } 7\end{array}$ & $\begin{array}{l}\text { MT: Posterior hip mobilization grades III/IV bilaterally, Hip IR/ER mobilization with movement (MWM) bilaterally } \\
\text { TE: } \\
\text { Warm-up: Rower } \times 750 \text { meters, } \\
\text { Mobility: Quadruped rock backs } \times 20 \text { each with leg in cross body position, Leg elevated lunge for posterior hip } \\
\text { mobility } \\
\text { Core Stability and Strength: } \\
\text { Circuit A } 2 \text { rounds: Single leg Romanian Dead lifts with dowel assist } \times 10 \text { each side, Single-leg hip thruster } \times 8-10 \\
\text { from bench, Side-step up with opposite knee drive with torso angled away from box with } 4 \text { kg KB ball hold } \times 10 \text { each } \\
\text { side } \\
\text { HEP: Updated detailed program can be found in Table } 6 \text {. }\end{array}$ \\
\hline
\end{tabular}

*MT= manual therapy, $\mathrm{TE}=$ therapeutic exercise, $\mathrm{HEP}=$ home exercise program, $\mathrm{CT}=$ cervicothoracic, $\mathrm{HK}=$ half-kneeling, WGS= world's greatest stretch, $\mathrm{IR}=$ internal rotation, $\mathrm{ER}=\mathrm{ex}-$ ternal rotation

tension. Although, the likelihood of these characteristics to continue to occur in his swing has been reduced from his initial screen. When re-evaluating his swing, he still demonstrates the following characteristics: slide, loss of posture, early extension, and RSA. He no longer demonstrates the characteristic of swaying during his back swing which could be a result of improving his left hip IR and improving his understanding of upper and lower body dissociation. Although he demonstrated a slide during the downswing, it improved since his initial swing evaluation.

\section{DISCUSSION}

This case report demonstrates the application of the TPI level one screen, a golf swing evaluation, and the principles of regional interdependence in guiding the initial evaluation, overall POC, exercise selection, and HEP for the golfing athlete with low back pain. With this approach, the subject was able to make significant progress with his overall mobility and core stability which allowed him to resume playing golf and weightlifting without experiencing any pain.

Initial focus was on restoring the joint mobility in the thoracic spine as well as the hips to help alleviate the stress being placed on the lower back. This is consistent with the principle of regional interdependence and has been shown to be effective in previous case studies for addressing the rotational athlete with LBP. ${ }^{13-15}$ Although he did not present with the common pattern of a greater deficit in lead hip IR (right hip for a left-handed golfer) from previous lit- erature, he did demonstrate deficits in hip IR bilaterally and with some soft-tissue extensibility. This was addressed with manual therapy to both regions and then followed up with therapeutic exercise to help maintain these gains. Once this had been improved as noted by his asterisk signs of MSR and MSE, the treatment session would transition to focus on motor control activities to help upper and lower body dissociation with a specific focus on the hips and lower back. TPI instructors discuss the importance of being able to dissociate to allow for the proper power transfer up from the ground during the swing as demonstrated by a proper kinematic sequence. ${ }^{4}$

According to Evans et. al, this patient was at a higher risk for experiencing low back pain as his BMI was $23 \mathrm{~kg} / \mathrm{m}^{2,5}$ Although his side plank deficits were not largely different side to side, his overall hold times in all positions were poor. Anderson et al. found the average side-plank hold in healthy males with an average age of 28 in their study to be $68.2 \mathrm{sec}$ on the right and $69.5 \mathrm{sec}$ on the left. ${ }^{19}$ Their Biering-Sorensen on average was 95.6 seconds. ${ }^{19}$ These all improved over the course of his care but would still be lower than the average for his age and exercise category. McGill et al. compared plank hold ratios in healthy subjects and those with LBP. ${ }^{20}$ One large difference was the extension holds (performed using the Biering-Sorensen test) which was much better in those without LBP. When looking at the ratios dividing the side-plank holds by the extension hold time, they are .57 and .58 for the healthy group while the LBP group was at a 1.20 The current subject had an initial ratio of 2 for the right side and 2.4 for the left side when 
Table 6: Home Exercise Program given at discharge

\begin{tabular}{|c|c|c|}
\hline Exercise & Repetitions & Weight \\
\hline \multicolumn{3}{|c|}{ Mobility/Dynamic Warm-Up } \\
\hline \multicolumn{3}{|l|}{ World's Greatest Stretch } \\
\hline \multicolumn{3}{|l|}{ Walking Figure 4} \\
\hline \multicolumn{3}{|l|}{ Inchworm into Reverse Toe Touch } \\
\hline Open Books/Thread the needle & X 15 ea side & \\
\hline Heel rock with leg crossed behind body & X 15 ea side & \\
\hline Leg elevated lunge for hip mobility & X 10 ea side & \\
\hline \multicolumn{3}{|c|}{ Motor Control- perform as a circuit $\times 3$ rounds } \\
\hline Torso turns with hips at wall & X 10 ea direction & \\
\hline Single leg stork turns with dowel & X 10 ea direction & \\
\hline Bird-dogs & X 10 ea leg & \\
\hline \multicolumn{3}{|c|}{ Strength Circuit A x 3} \\
\hline SL RDL & X 12 ea side & BW, progress to DB hold in hand \\
\hline SL hip thruster from bench/couch & X 10 ea side & BW, progress to weight across hips \\
\hline Front plank with leg extension lifts & X15 ea & BW \\
\hline \multicolumn{3}{|c|}{ Strength Circuit B x 3} \\
\hline SL paloff press (close leg down) & X 15 ea side & Heavy resistance band \\
\hline Side-stepping with Band & $\times 20$ yards & Green Theraband \\
\hline Modified side-plank with row & X 15 ea side & Band/DB \\
\hline
\end{tabular}

*SL= Single Leg, $\mathrm{BW}=$ Body Weight, $\mathrm{DB}=$ Dumbbell

†Alternative Exercises for Substitution during strength program: Goblet squat with $15 \mathrm{lb}$ KB x 12, Lateral tap downs x 12 ea, Kettle bell Deadlift with $12 \mathrm{~kg} \times 12$, Half-kneeling chops without moving the trunk $\mathrm{x} 10$ ea side

comparing his side planks/Biering-Sorensen, which is much more consistent with the LBP group from the above-mentioned study. This was improved to a ratio of 1.6 by the end of our POC but is still more consistent with the LBP group and could use continued focus for his HEP. To address these deficits in core stability a variety of exercises were performed and included a variety of positions. Outside of performing plank holds with various extremity movements, the subject also performed half-kneeling chops, and pallof presses in multiple positions (Shoulder-width, Lunge, SL stance) to improve his core stability. These exercises add an anti-rotation component that is important when trying to train the core musculature, particularly when training the rotational athlete. Core activation would also be obtained during his LE strengthening through medicine ball or kettlebell holds.

The TPI level one screen provides further functional information about how ab athlete moves within their golf swing, which can be important when it is one of the paingenerating movements. It can provide an asterisk sign that can be re-checked by the therapist to assess if their treatments are making any changes and is directly related to their overall goal. Using the Body-Swing connection identifies swing characteristics that may be present during the swing evaluation. This is particularly important when evaluating low back pain as it is important to identify the likelihood of S-posture, RSA, and early extension, since they have all been associated with LBP. If these characteristics are not being addressed with their swing coach, the golfer would stay at a higher risk of their LBP to reoccur.

The golf swing evaluation can help the therapist put into context some of their evaluation findings such as weak lateral hip stabilizers or decreased hip mobility with a golfer who sways or slides during their swing. It also allows the medical provider to be able to discuss their findings with the player's swing coach as they look to improve upon any injury inducing mechanics or be aware of functional deficits that may need to be intentionally compensated for such as turning the feet out to help improve one's hip mobility in their swing. This patient was not currently working with a golf instructor; therefore, he was not able to fully address these characteristics. Ideally, each golfer would be working with a multidisciplinary team including a medical provider, golf professional, and fitness professional to maximize their results as this has been found to be the best approach for rehabilitation and prevention of further injury. ${ }^{4,21}$ Further research is necessary to fully understand how this comprehensive evaluation can enhance the rehabilitation approach to the golfing athlete with LBP.

\section{LIMITATIONS}

The single subject that is followed in a case report limits the 
conclusions that can be drawn according to the results, and cause and effect cannot be assumed. This affects the utility of using this approach on other subjects with similar presentations. Exercise prescription related to the TPI screen may vary between treating therapists based on their own judgement and experience. There is no way to determine if other treatment approaches for this patient would have elicited similar results. The POC for this patient was also cut short due to the clinic closing amid COVID-19 restrictions which may have limited the overall progress that was observed.

\section{CONCLUSION}

The results of this case report indicate that the application of the TPI level one screen and a golf swing evaluation were helpful in providing functional movement screening during the initial evaluation and assisting with treatment selection in a golfing athlete with low back pain. In this case, the TPI level one screen and the swing evaluation allowed the therapist to learn more about how the patient's body responded to the functional demands of his sport and identify areas where compensations were occurring that may not be identified with a traditional physical therapy exam. This case report demonstrated that utilizing TPI-based exam procedures as well as considering the principle of regional interdependence were effective contributors to the evaluation and treatment of the golfing athlete with low back pain.

\section{CONFLICT OF INTEREST}

The author reports no conflicts of interest.

Submitted: August 04, 2020 CDT, Accepted: November 26, 2020 CDT 


\section{REFERENCES}

1. McHardy AJ, Pollard HP, Luo K. Golf-related lower back injuries: An epidemiological survey. J Chiropr Med. 2007;6(1):20-26. doi:10.1016/j.jcme.2007.02.010

2. Gosheger G, Liem D, Ludwig K, Greshake O, Winkelmann W. Injuries and overuse syndromes in golf. Am J Sports Med. 2003;31(3):438-443. doi:10.117 7/03635465030310031901

3. Rose G. Common lower back injuries. Titleist Performance Institute Level 2 Medical Online Course. In: 2018 December.

4. Blackburn M, Gill L, Glass J. Titleist Performance Institute Level 1 Seminar. Presented at the: 2018 August 16-17; Dallas, TX.

5. Evans K, Refshauge KM, Adams R, Aliprandi L. Predictors of low back pain in young elite golfers: A preliminary study. Phys Ther Sport. 2005;6(3):122-130. doi:10.1016/i.ptsp.2005.05.003

6. Murray E, Birley E, Twycross-Lewis R, Morrissey D. The relationship between hip rotation range of movement and low back pain prevalence in amateur golfers: An observational study. Phys Ther Sport. 2009;10(4):131-135. doi:10.1016/i.ptsp.2009.08.002

7. Vad VB, Bhat AL, Basrai D, Gebeh A, Aspergren DD, Andrews JR. Low back pain in professional golfers: The role of associated hip and low back range-ofmotion deficits. Am J Sports Med. 2004;32(2):494-497. doi:10.1177/0363546503261729

8. Gulgin H, Armstrong C. Passive hip rotation range of motion in LPGA golfers. Clin Kinesiol. 2008;62(2).

9. Kim S-B, You JS, Kwon O-Y, Yi C-H. Lumbopelvic kinematic characteristics of golfers with limited hip rotation. Am J Sports Med. 2015;43(1):113-120. doi:1 $0.1177 / 0363546514555698$

10. Lindsay D, Horton J. Comparison of spine motion in elite golfers with and without low back pain. $J$ Sports Sci. 2002;20(8):599-605. doi:10.1080/02640410 $\underline{2320183158}$

11. Shimamura KK, Cheatham S, Chung W, et al. Regional interdependence of the hip and lumbopelvic region in division ii collegiate level baseball pitchers: A preliminary study. Int I Sports Phys Ther 2015;10(1):1-12. https://pubmed.ncbi.nlm.nih.gov/25 709857/.
12. Cole MH, Grimshaw PN. Trunk muscle onset and cessation in golfers with and without low back pain. $J$ Biomech. 2008;41(13):2829-2833. doi:10.1016/i.jbiom ech.2008.07.004

13. Lejkowski PM, Poulsen E. Elimination of intermittent chronic low back pain in a recreational golfer following improvement of hip range of motion impairments. J Bodyw Mov Ther. 2013;17(4):448-452. doi:10.1016/j.jbmt.2013.01.004

14. Kaplan A. Application of regional interdependence in treating an adolescent athlete with low back pain: A case report. Orthop Pract. 2016;28(4:16):254-262. https://www.orthopt.org/uplo ads/content files/files/Kaplan.pdf.

15. Goshtigian GR, Swanson BT. Using the selective functional movement assessment and regional interdependence theory to guide treatment of an athlete with back pain: A case report. Int J Sports Phys Ther. 2016;11(4):575-595. https://www.ncbi.nlm.ni h.gov/pmc/articles/PMC4970848/.

16. Fairbank JCT, Pynsent PB. The oswestry disability index. Spine. 2000;25(22):2940-2952; discussion 52. d oi:10.1097/00007632-200011150-00017

17. Waddell G, Newton M, Henderson I, Somerville D, Main CJ. A fear-avoidance beliefs questionnaire (FABQ) and the role of fear-avoidance beliefs in chronic low back pain and disability. Pain. 1993;52(2):157-168. doi:10.1016/0304-3959(93)9012 7-b

18. George SZ, Fritz JM, Mcneil DW. Fear-avoidance beliefs as measured by the fear-avoidance beliefs questionnaire: Change in fear-avoidance beliefs questionnaire is predictive of change in self-report of disability and pain intensity for patients with acute low back pain. Clin J Pain. 2006;22(2):197-203. doi:1 0.1097/01.ajp.0000148627.92498.54

19. Anderson D, Barthelemy L, Gmach R, et al. Core strength testing: developing normative data for three clinical tests [thesis]. Minneapolis: St. Catherine University. 2014.

20. Mcgill S, Grenier S, Bluhm M, Preuss R, Brown S, Russell C. Previous history of LBP with work loss is related to lingering deficits in biomechanical, physiological, personal, psychosocial and motor control characteristics. Ergonomics. 2003;46(7):731-746. doi:10.1080/00140130310000901 34 
21. Finn C. Rehabilitation of low back pain in golfers.

Sports Health. 2013;5(4):313-319. doi:10.1177/194173

$\underline{8113479893}$ 